\title{
Synthesis and Characterization of Novel Sulphanilamide/Epoxy Resin Modified Polyester for Thermal Stability and Impact Strength
}

\author{
Mohammed H. M. Alhousami1*, Ahmed S. N. Al-Kamali', Anjali A. Athawale² \\ ${ }^{1}$ Department of Industrial Chemistry, Faculty of Applied Science, University of Taiz, Taiz, Republic of Yemen \\ ${ }^{2}$ Department of Chemistry, University of Pune, Pune, India \\ Email: ${ }^{*}$ alhousami@yahoo.com
}

Received 27 August 2014; revised 25 September 2014; accepted 3 October 2014

Copyright (C 2014 by authors and Scientific Research Publishing Inc.

This work is licensed under the Creative Commons Attribution International License (CC BY).

http://creativecommons.org/licenses/by/4.0/

C) (i) Open Access

\section{Abstract}

The synthesis of thermally stable Tetra-di-glycidyl ether bisphenol-A (TDGEBA) Epoxy resin and Sulphanilamide (SAA) have been synthesized from (SAA) and TDGEBA by in situ polymerization technique to obtain Tetra-di-glycidyl ether bisphenol-A Sulphanilamide (TDGEBA/SAA) Epoxy resin and modified with various percentages of polyester (PE) to obtain Tetra diglycidyl ether bisphenol-A Sulphanilamide polyester (TDGEBA/SAA-PE), highly cross-linked thermosetting polymer network. These materials were cured with triethylenetetramine TETA (hardener) to obtain highly cross-linked thermosetting resin. The physical properties of the resulting blends were evaluated by measuring the impact strength of (TDGEBA/SAA-PE) (increased more than $30 \%$ than the unmodified epoxy resin) and hardness that is found to be higher than unmodified epoxy resin. Differential scanning calorimetry (DSC) and thermo gravimetric (TGA) analysis were also cured to assess the thermal behavior of the samples. DSC of the (TDGEBA/SAA) Epoxy resin cured with TETA showed exothermic reactions and the glass transition temperature $(\mathrm{Tg})$ shifted from $350^{\circ} \mathrm{C}$ to $400^{\circ} \mathrm{C}$ compared with uncured epoxy and the thermal stability of the TDGEBA/SAA epoxy resin modified increased with increasing of PE. Scanning Electron Microscopy (SEM) studied the morphology of the samples after unnotched impacts on fracture surfaces. These materials exhibited a higher degree of solvent resistance.

\section{Keywords}

Epoxy, Impact, Thermal Stability, SEM

\footnotetext{
${ }^{*}$ Corresponding author.

How to cite this paper: Alhousami, M.H.M., et al. (2014) Synthesis and Characterization of Novel Sulphanilamide/Epoxy Resin Modified Polyester for Thermal Stability and Impact Strength. Open Journal of Polymer Chemistry, 4, 115-127. 


\section{Introduction}

The modern technology development needs reliable high-performance composite materials of lightweight with excellent thermal and mechanical properties. Epoxy resins based on diglycidyl ether of bisphenol-A have been used extensively as thermosetting materials in the development of high-performance lightweight fiber reinforced composites. Epoxy resin exhibits many desirable properties, such as high strength and modulus, excellent chemical and solvent resistance, good thermal and electrical properties and outstanding adhesions [1]-[8].

Epoxy resins are widely used as molding compounds and encapsulation materials. However, cured epoxy resins are generally brittle and they exhibit inferior weathering resistance. These are the major factors that inhibit further proliferation of epoxy resin into many advanced industrial application and these have resulted in many studies devoted to toughening them without compromising their stress-strain and thermal properties.

Of late, many efforts have been made to improve the toughness of the cured epoxy resin. Most of the studies on the modification of epoxy resins had been carried out by ATBN (amine-terminated acrylonitrile-butadiene), HTBN (hydroxyl-terminated acrylonitrile-butadiene) rubbers, functionally terminated acrylates, poly (phenylene dxide) and alkaline oxides [9]-[11]. Toughing such modified epoxy resins with these polymeric materials improved its impact characteristics; it failed to increase the physic-mechanical properties of cured epoxy resin when they were used for high temperature applications.

Therefore, in this work, our aim was to improve the thermal and mechanical properties of epoxy resins using aromatic amine, together with polyester. Aliphatic and aromatic amines due to presence of active hydrogen can cause the ring opening of epoxy resin skeleton and hence are commonly used as curing agents. Aliphatic amines used commercially include ethylene amine derivatives and polyether amines [12]-[14].

The networks cured with aromatic amines have improved solvent resistance and performance at elevated temperatures compared to the networks cured with aliphatic amines alone.

Common aromatic amines used as epoxy cross-linking agents include m-phenylenediamine, p,p-diaminodiphenylmethane and p,pdiaminodiphenylsulfone [15]-[19].

Hence, in the present study, an attempt has been made to improve both toughness and thermal behave of epoxy resin without an appreciable loss in strength properties by forming an inter cross-linked network of diglacydil ether bisphenol-A DGEBA epoxy resin and aromatic amine (sulphanilamide) SAA cured with Triethylene tetramine aliphatic amine (hardener) TETA modified polyester, aromatic amine (sulphanilamide). Aromatic amines exhibit UV resistance, solvent resistance, chemical resistance, high impact strength, good hardness high thermal stability and highest cross-linking [15]-[19].

\section{Experimental}

\subsection{Materials}

All the chemicals used were of AR grade. DGEBA epoxy resin was procured from Shimo Resin Pvt. Ltd. under the trade name SHIMOREZ-400, the density at $25^{\circ} \mathrm{C}$ being $1.11 \mathrm{~g} / \mathrm{ml}$, viscosity at $25^{\circ} \mathrm{C}, 12,000 \pm 300 \mathrm{mPaS}$, and sulphanilamide, Malikanhydride pthalicanhydride, propylineglycol, adipic acid, diethylene glycol, 1,4-butanediol, Chloroform, acetone, hexane and Benzoylperoxide were commercial grade products (Lopa) while, triethylenetetramine (TETA) acting as curing agent was from the Robert Johnson Company, and polyester (PE) compound was synthesized from adipic acid, ethylene glycol and 1,4-butanediol as reported previously [20].

\subsection{Preparation Methods}

In the present work,the Tetra diglycidyl ether of bisphenol A (DGEBA) Sulphanilamide (TDGEBA/SAA) Epoxy resin was synthesised by mixing different concentrations of commercial grade of DGEBA Epoxy resin (1 - $4 \mathrm{~mol})$ with a fixed concentration of sulphanilamide $(1 \mathrm{~mol})$ to replace all $\mathrm{H}$ atoms of sulphanilamide. In this case, initially sulphanilamide was added to the reaction three-neck flasks and heated to $160^{\circ} \mathrm{C}$ until sulphanilamide melted and mechanical stirring began. After this, DGEBA epoxy resin was added and the temperature was raised from $160^{\circ} \mathrm{C}$ to $200^{\circ} \mathrm{C}$ over a period of 1 hour. The temperature was maintained at $200^{\circ} \mathrm{C}$ and the reaction was completed after $3 \mathrm{~h}$. The product was red in colour, homogeneous, viscous and transparent in nature. The reaction product was permitted to cool under nitrogen atmosphere and the product initially; the melting of Tetra diglycidyl ether bisphenol-A Sulphanilamide (TDGEBA/SAA) Epoxy resin mixture does show the semi liquid 
crystal properties and was stored in an amber coloured bottle.

The epoxy resin was found to solidify after cooling at room temperature and the yield was $91.0 \%$. The chemical reaction of the product is given below Scheme 1 .

The Tetra-diglycidyl ether bisphenol-A (TDGEBA/SAA) epoxy resin monomer has been developed with modified by varies amount polyester PE with TETA like hardener in a beaker. The mixture was stirred to obtain a paste, which was poured in a test tube then adding benzoylperoxide like initiator and kept in an oil bath maintained at a fixed temperature and the hardening time was determined. A series of samples were prepared by varying the ratio of polyester monomer.

\subsection{Solvent Resistance}

Solvent resistance was measured for acetone, chloroform, and hexane by ASTM standards. The apparatus used was made entirely of glass. This was engineered so that the condensed extracting solvent is in contact with the sample and is at temperature not much below its boiling point. Accurately weighed $0.2 \mathrm{~g}$ samples were placed in a filter paper basket and then introduced in the siphon cup of the soxhlet and extracted individually with acetone, chloroform and hexane for 8 hours. The samples were dried after extraction in vacuum oven at $40^{\circ} \mathrm{C}$ until constant weight was obtained. The solvent unextractable value (x) was calculated [20]-[23].

\subsection{Mechanical Properties}

The hardness of samples was measured on a Shore Hardness Tester. Dunomekes with reference to ASTM standard on unnotched Izod impact strengths were measured at ambient conditions according to the ASTM D256 method, by an Impact Tester from IZOD make ATS Faar S.P.A. Italy [24]-[27].

\subsection{Thermal Analysis}

Thermal analysis of the samples were performed on TA instrument Model-Universal V 2.6D. The samples were analyzed in $\mathrm{N}_{2}$ atmosphere at a scan rate of $10^{\circ} \mathrm{C} \mathrm{min}^{-1}$. The TGA and DSC were recorded between a temperature range from $\mathrm{RT}$ to $1000^{\circ} \mathrm{C}[28][29]$.

\subsection{Morphology Analysis}

The morphology of the samples was investigated by SEM analysis. The SEM instrument JEOL, JSM-6360A was used for the same.

\section{Results and Discussion}

Pure epoxy resins have been observed to have a brittle nature and hence they exhibit poor mechanical properties [7] [25] [26]. However, applications in space industries and extreme conditions require the material to be thermally stable bearing good mechanical properties. In the present work, a set of Epoxy resins have been synthesized by adding aromatic amine such as Sulphanilamide. DSC and TGA using different heating rates investigated the curing reaction of the thermoset Liquid epoxy monomer (DGEBA) in the presence of SAA. The chemical reactions involved are shown in Scheme 1.

The diamine SAA has two different amine functions of unequal reactivity and leads to the formation of a smectic phase when it is used as a curing agent [30]-[32].

Concerning the liquid epoxy DGEBA/SAA monomers has been observed to have a brittle nature and hence the exhibit poor mechanical properties comparing with the curing reaction of the Tetra diglycidyl ether bisphenol-A Sulphanilamide TDGEBA/SAA epoxy monomer with Triethylenetetramine (TETA) like hardener and modified with (PE).

In the present work, a set of the TDGEBP/SAA epoxy monomer have been modified by adding various ratio of (PE). The comparison of the results of hardening time, mechanical properties and solvent resistance shown in Table 2 obtained for each of the sets reveals differences in each case. The chemical structure of the curing of liquid Tetra diglycidyl ether bisphenol-A Sulphanilamide TDGEBA/SAA epoxy monomer with (TETA) is as shown below Scheme 2.

In case of liquid epoxy TDGEBP/SAA, monomers modified with (PE) a set of Epoxy resins samples have been synthesized by adding various ratio of (PE) in the present of (TETA) like hardener Table 1 . The chemical 
structure of the modified of liquid TDGEBA/SAA epoxy monomers with (PE) in the present of (TETA) as shown below Scheme 3.

$\mathrm{PE}$ being in nature would render or impart rigidity to a greater extent compared to unmodified epoxy resins.

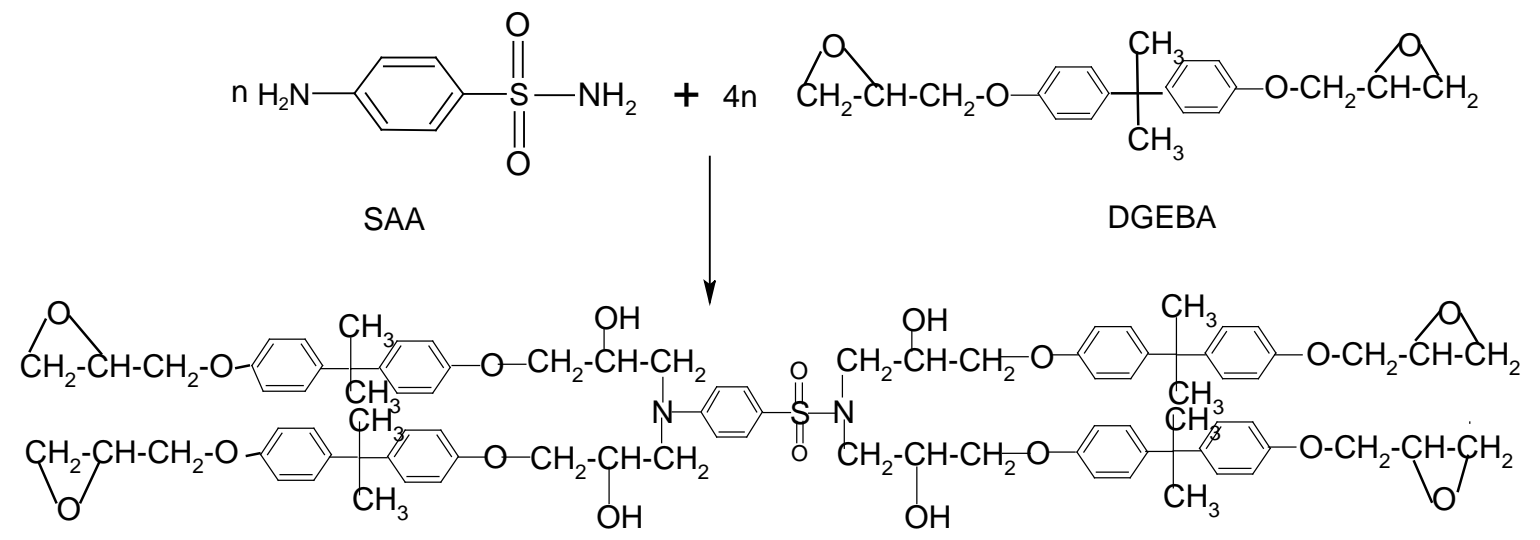

Scheme 1. Synthesis of tetra-di-glycidyl ether bisphenol-A (TDGEBA/SAA) epoxy resin.
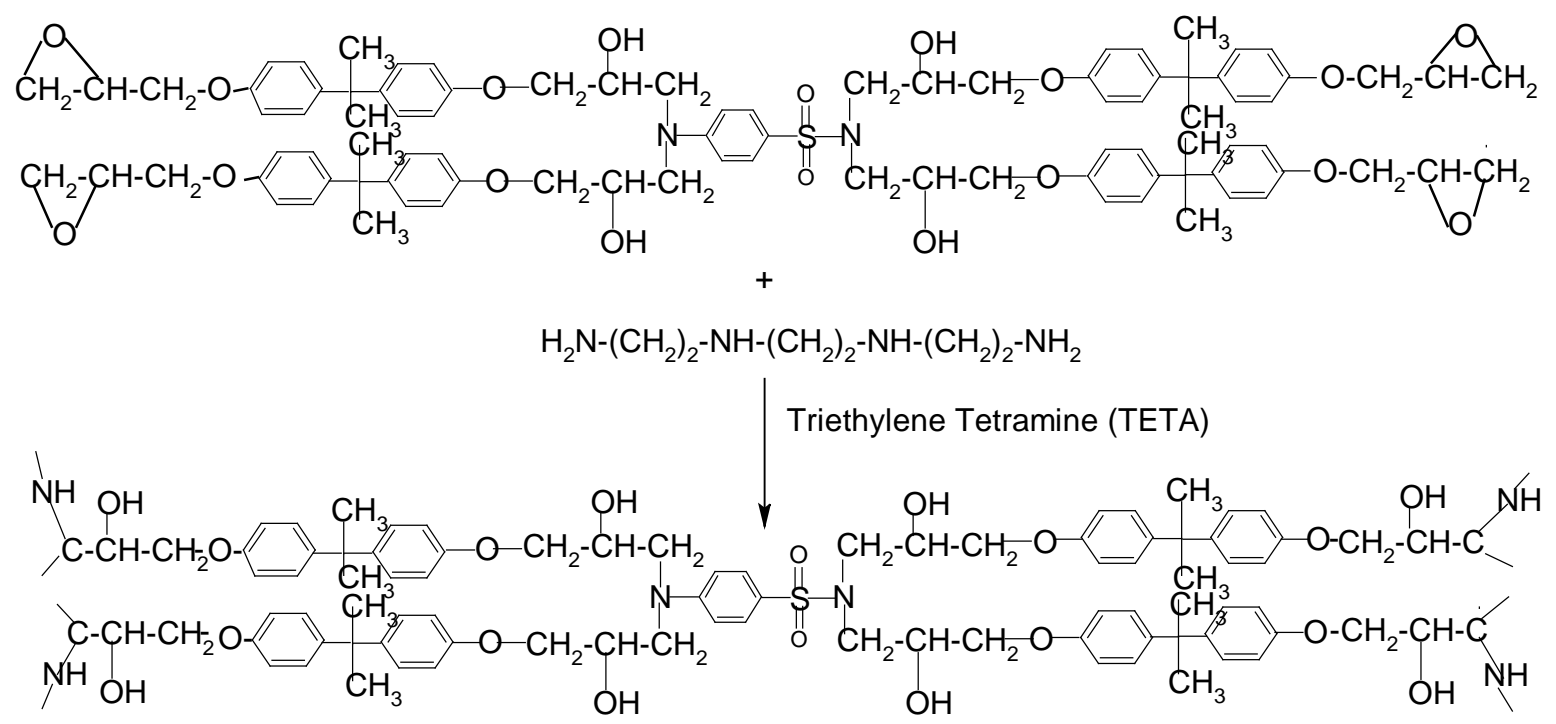

Scheme 2. Curing reaction of TDGEBA/SAA epoxy with (TETA) system.

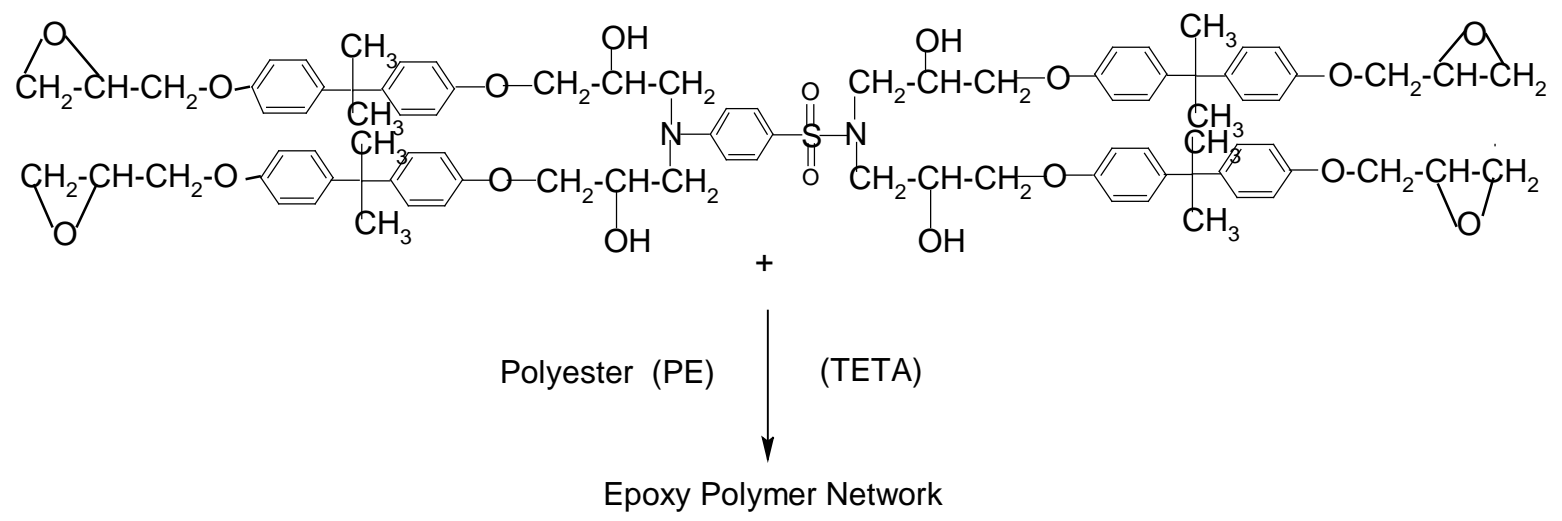


Table 1. Thermo gravimetric data obtained from the TGA-analysis of neat TDGEBA/SAA (100\%) epoxy resin and modified with polyester PE in presence of benzoyl peroxide as initiator at $\left(85^{\circ} \mathrm{C}\right)$.

\begin{tabular}{|c|c|c|c|c|}
\hline Reactant (g) & $\begin{array}{c}\text { Temp. of } 5 \% \\
\text { Decomposition }\left({ }^{\circ} \mathrm{C}\right)\end{array}$ & $\begin{array}{c}\text { Temp. of } 20 \% \\
\text { Decomposition }\left({ }^{\circ} \mathrm{C}\right)\end{array}$ & $\begin{array}{c}\text { Temp. of } 50 \% \\
\text { Decomposition }\left({ }^{\circ} \mathrm{C}\right)\end{array}$ & $\mathrm{T}_{\mathrm{g}}\left({ }^{\circ} \mathrm{C}\right)$ \\
\hline Neat TDGEBA/SAA & 110.0 & 270.0 & 380.0 & 350.0 \\
\hline TDGEBA/SAA (100\%) & 312.0 & 386.0 & 432.0 & 400.0 \\
\hline TDGEBA/SAA-P (95/5) & 296.0 & 376.0 & 428.0 & - \\
\hline TDGEBA/SAA-P (90/10) & 295.0 & 372.0 & 421.0 & - \\
\hline TDGEBA/SAA-P (85/15) & 298.0 & 370.0 & 420.0 & - \\
\hline TDGEBA/SAA-P (80/20) & 285.0 & 368.0 & 418.0 & - \\
\hline TDGEBA/SAA-P (70/30) & 280.0 & 366.0 & 405.0 & - \\
\hline TDGEBA/SAA-P (60/40) & 275.0 & 360.0 & 405.0 & - \\
\hline TDGEBA/SAA-P (50/50) & 275.0 & 357.0 & 395.0 & - \\
\hline TDGEBA/SAA-P (40/60) & 265.0 & 350.0 & 395.0 & - \\
\hline
\end{tabular}

Table 2. Hardening time, Solvent resistance and mechanical properties of neat TDGEBA/SAA (100 \%) cured with TETA as well as epoxy modified with polyester in presence of benzoyl peroxide as initiator at $\left(85^{\circ} \mathrm{C}\right)$.

\begin{tabular}{|c|c|c|c|c|c|c|}
\hline \multirow{2}{*}{ Reactant (g) } & \multirow{2}{*}{$\begin{array}{l}\text { Hardening Time } \\
\text { (h) }\end{array}$} & \multicolumn{3}{|c|}{ Solvent Resistance \% } & \multicolumn{2}{|c|}{ Mechanical Properties } \\
\hline & & Acetone & Chloroform & Hexane & Izod $\mathrm{Jm}^{-2}$ & Hardness \\
\hline Neat TDGEBA/SAA (100\%) & 2.30 & 98.0 & 96.0 & 98.0 & 2423.2 & 76.0 \\
\hline TDGEBA/SAA-P (95/5) & 2.35 & 98.0 & 94.0 & 94.0 & 2823.6 & 78.0 \\
\hline TDGEBA/SAA-P (90/10) & 2.40 & 97.0 & 94.0 & 97.0 & 3367.0 & 79.0 \\
\hline TDGEBA/SAA-P (85/15) & 2.40 & 98.0 & 98.0 & 98.0 & 3864.0 & 80.0 \\
\hline TDGEBA/SAA-P (80/20) & 2.50 & 98.0 & 98.0 & 98.0 & 4688.5 & 83.0 \\
\hline TDGEBA/SAA-P (70/30) & 2.50 & 98.0 & 97.0 & 96.0 & 4952.3 & 74.0 \\
\hline TDGEBA/SAA-P (60/40) & 3.0 & 100.0 & 98.0 & 99.0 & 5715.0 & 72.0 \\
\hline TDGEBA/SAA-P (50/50) & 3.10 & 100.0 & 100.0 & 100.0 & 6724.0 & 71.0 \\
\hline TDGEBA/SAA-P (40/60) & 3.20 & 100.0 & 100.0 & 100.0 & 8012.0 & 70.0 \\
\hline
\end{tabular}

\subsection{Differential Scanning Calorimetry (DSC)}

The (DSC) and TGA using different heating rates Figure 1 investigated the uncuring and curing reaction of TDGEBA/SAA with TETA.

Initially, the melting of the TDGEBP/SAA without curing with TETA mixture does not show the LC properties since an isotropic liquid is formed above the melting point [33]-[35]. Then, as the reaction between epoxy and amine proceeds, a LC texture is developed, which is locked in the crosslinked network by the nematic arrangement. Depending on the heating rate, the DSC Figure 1(a) thermograms of the curing process shows three endothermal peaks and two or three exothermal peaks. Generally, the exothermal peaks appear, together with endothermal peaks, when the samples are cured at low heating rates Figure 1(a) shows an example of the DSC thermograms for TDGEBP/SAA mixture recorded between a temperature range from RT to $600^{\circ} \mathrm{C}$. The first two endothermal peaks observed in the temperature range between $200^{\circ} \mathrm{C}$ and $400^{\circ} \mathrm{C}$ are assigned to the melting of the individual components of the mixture studied. With increase of temperature above $400^{\circ} \mathrm{C}$, the DSC curve in Figure 1(a) shows three exothermic peaks [33]-[35]. Thermal stability of the TDGEBA/SAA was investigated by TGA, as shown in Figure 1(b). The amine bonds degrade in two steps owing to the initial degradation of the hydroxyl functionalities at $100^{\circ} \mathrm{C}-350^{\circ} \mathrm{C}$. The $5 \%$ weight loss of amine bound was at $110^{\circ} \mathrm{C}$ Table 1 . 


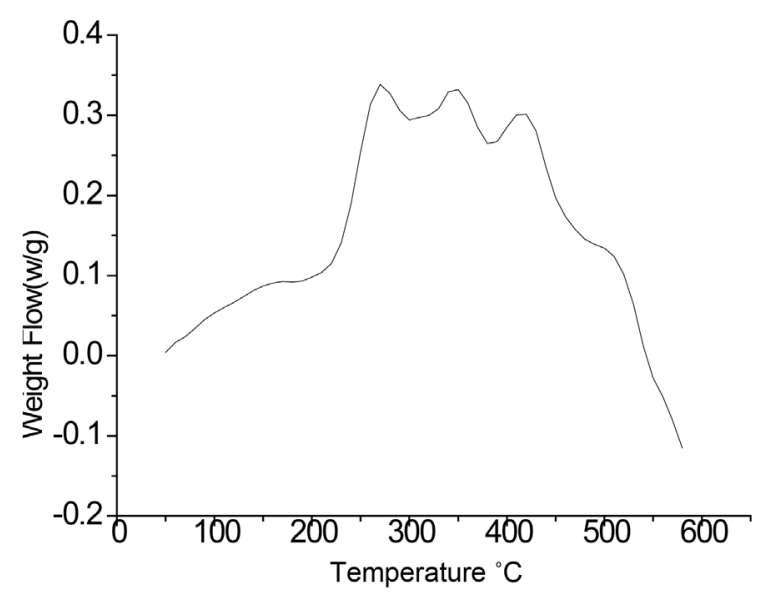

(a)

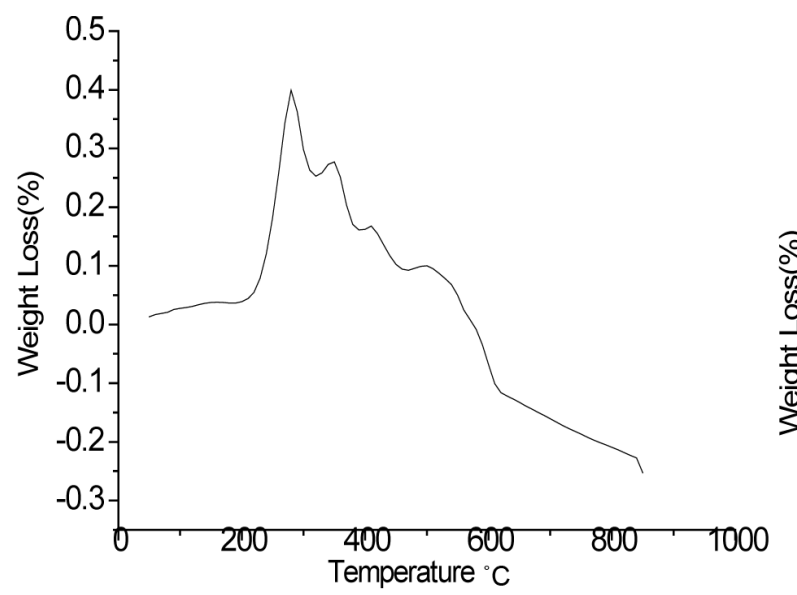

(c)

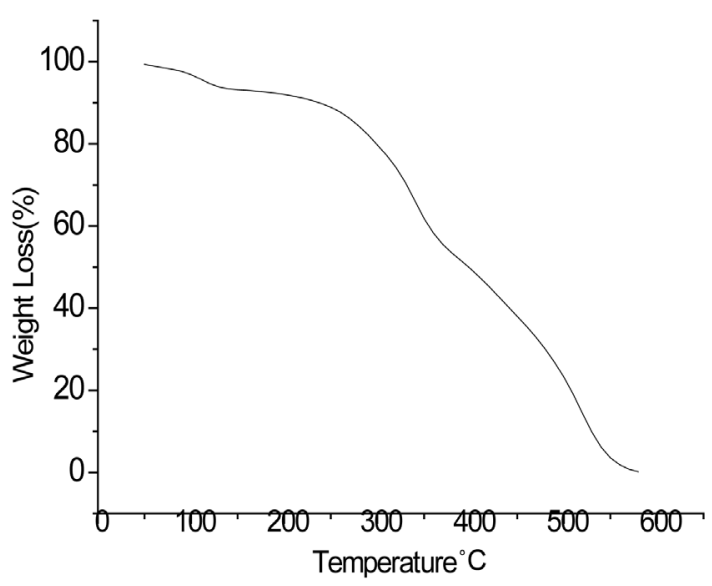

(b)

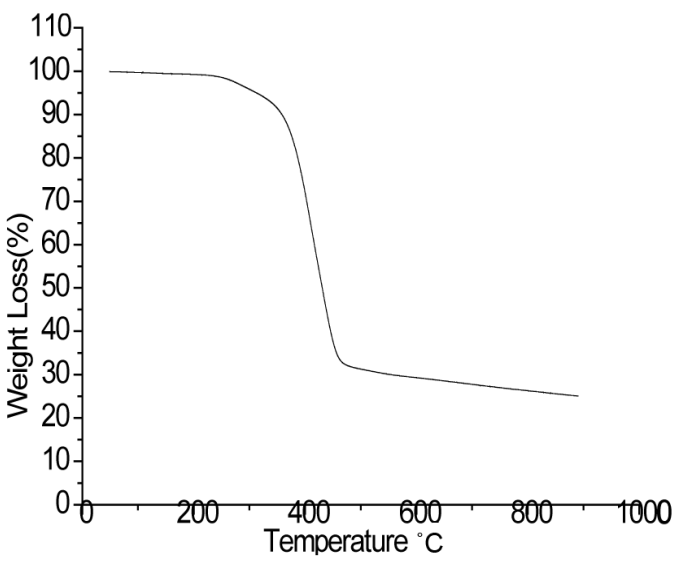

(d)

Figure 1. DSC and TGA plots of uncuring TDGEBA/SAA epoxy and curing with (0.1 g) TETA. (a) Uncuring TDGEBA/ SAA epoxy resin (b) Curing TDGEBA/SAA epoxy resin; (a) (b) Represent DSC and TGA plots of uncuring TDGEBA/SAA respectively; (c) (d) Represent DSC and TGA plots of curing TDGEBA/SAA respectively, in presence of benzoyl peroxide as initiator at $\left(85^{\circ} \mathrm{C}\right)$.

The TGA degradation profiles of TDGEBA/SAA samples also show two distinct thermal stages. The first stage of weight loss is due to the degradation of epoxy at $150-300$, and the second due to the amine bonds at $300^{\circ} \mathrm{C}-400^{\circ} \mathrm{C}$. The $5 \%$ weight loss temperatures are $150^{\circ} \mathrm{C}-300^{\circ} \mathrm{C}$ for the TDGEBA/SAA mixture, as seen from these degradation temperatures.

In case of the tetra diglycidyl ether bisphenol-A Sulphanilamide TDGEBA/SAA curing reaction with TETA like hardener was investigated by DSC and TGA Figure 1(c). The (DSC) was measured to monitor the curing TDGEBA/SAA epoxy with TETA. Figure 1(c). Represents the thermogram of the curing TDGEBA/SAA with TETA abroad isotherm appeared starting at $200^{\circ} \mathrm{C}$ and reaching a maximum at $400^{\circ} \mathrm{C}$. This exotherm representting the curing of epoxy almost disappeared for the cured at $650^{\circ} \mathrm{C}$. These DSC behaviors confirmed that curing of epoxy and formation of network structure between epoxy and TETA occurred by the $650^{\circ} \mathrm{C}$ cure.

The exothermic behavior, Tg and the results are summarized in Table 1. The Figure 1(d) shows the thermal stability of the TDGEBA/SAA with along with TETA sample was investigated by TGA. As shown in Figure 1 (d), degrades in two steps owing to the initial degradation of the hydroxyl functionalities at $293^{\circ} \mathrm{C}-400^{\circ} \mathrm{C}$. The $5 \%$ weight loss of amine bounds was at $312.0^{\circ} \mathrm{C}$ Table 1 . The TGA degradation profiles of TDGEBA/SAA with along with TETA sample show one distinct thermal stages. The stage of weight loss is due to the degradation of crosslinking between TDGEBA/SAA epoxy and TETA at $312.0^{\circ} \mathrm{C}-467^{\circ} \mathrm{C}$ and completely degradation more than $900^{\circ} \mathrm{C}$, as seen from these degradation temperatures Figure $1(\mathrm{~d})$. The Tg has been shafted from $350^{\circ} \mathrm{C}$ to 
$400^{\circ} \mathrm{C}$ in case of TDGEBA/SAA epoxy cured with TETA compared with uncured TDGEBA/SAA epoxy respectively. The thermal stability of the TDGEBA/SAA mixture using TETA, and superior to that of the epoxy cured with the standard diamines such as SAA alone which decomposes below $200^{\circ} \mathrm{C}$.

In case of curing reaction, the TDGEBA/SAA epoxy monomer curing with TETA and modified with PE in the presence of Benzoylperoxide like initiator. In these case a set of TDGEBA/SAA epoxy monomer have been synthesized by adding PE.The weight percentages of each of them were varied from $5-60$. Initially, samples were prepared by adding PE during synthesis, small amount $1.0 \mathrm{~g}$, of hardener such asTETA was added which led to the solidification of the product. The chemical reactions of the TDGEBA/SAA curing with TETA and modified with PE are shown in Scheme 2. These Samples was investigated by TGA as shown Figures 2(a)-(d).

Incorporation of PE into TDGEBA/SAA epoxy monomer observed to exhibit overall improves the thermal stability compeering with thermal stability of TDGEBA/SAA epoxy monomer without cured and modified with TETA and PE respectively as shown above Figure 1(b).

For the cured and modified of TDGEBA/SAA, epoxy monomer enhances degradation temperature proportionate to its percentage concentrating From Figures 2(a)-(d). It is observed that the thermal degradation temperature of TDGEBA/SAA epoxy monomer cured TETA and modified with varies percentage of PE are slightly decrees with increasing PE contents compeering with TDGEBA/SAA epoxy monomer cured with TETA alone. Figures 2(a)-(d) the degradation increasing is mainly due to of thermally unstable bounds of polyester structure PE. The plots of degradation temperature of TDGEBA/SAA epoxy modified system against PE concentration are presented in Figures 2(a)-(d) respectively. In Figure 1(d) TDGEBA/SAA epoxy cured with TETA alone the temperature required for $5 \%, 30 \%$ and $50 \%$ weight losses are $312^{\circ} \mathrm{C}, 416^{\circ} \mathrm{C}$ and $432^{\circ} \mathrm{C}$ whereas the temper-

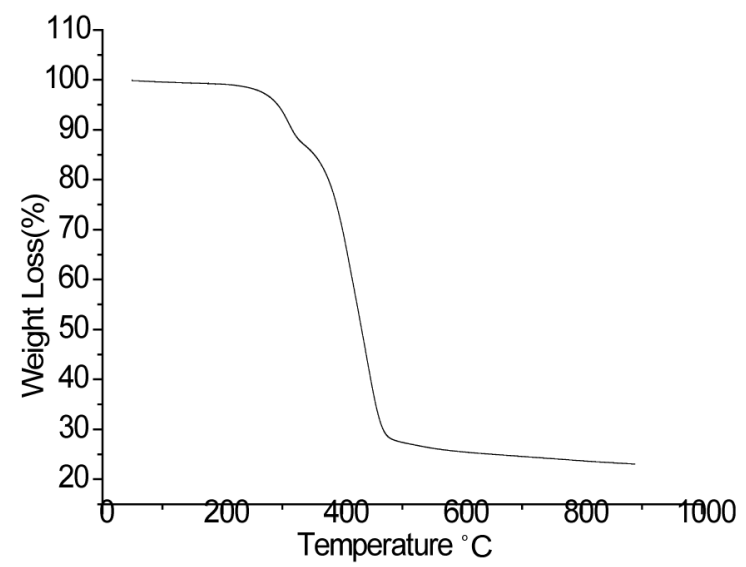

(a)

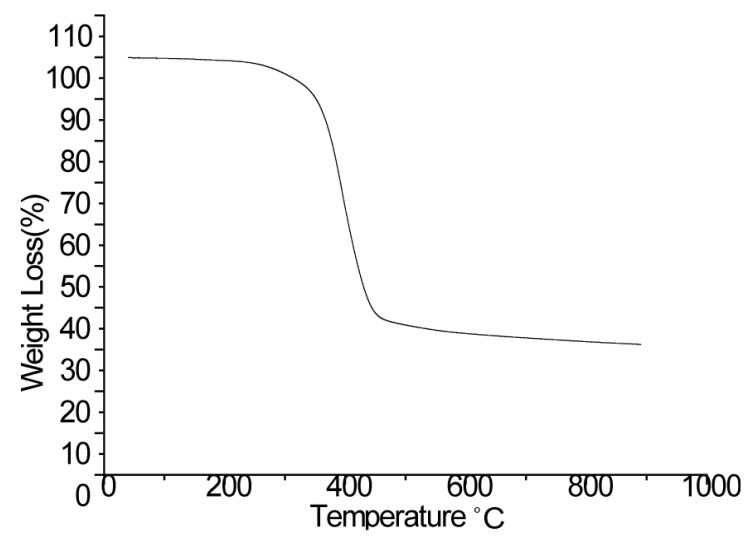

(a)

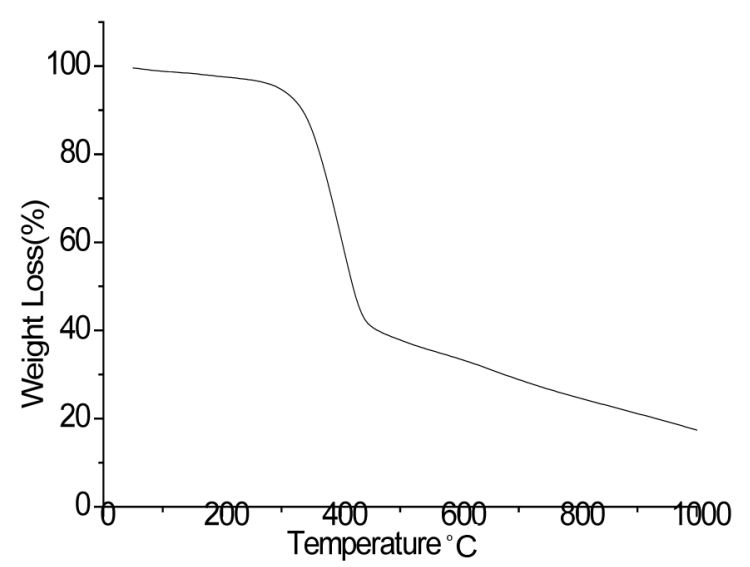

(b)

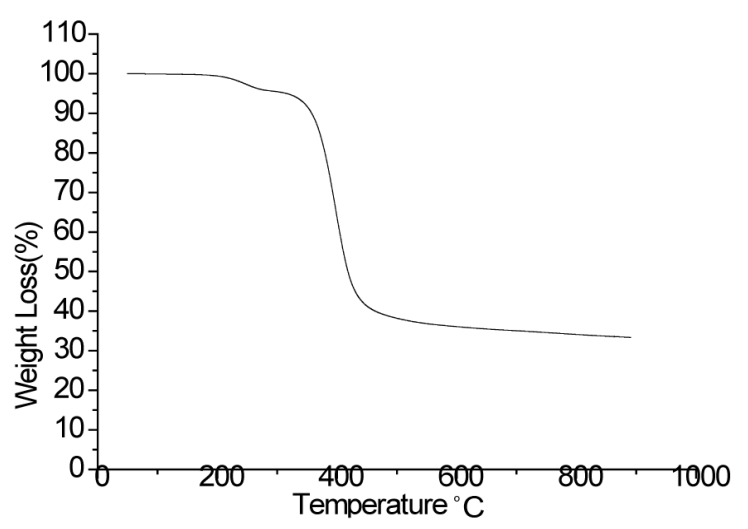

(d)

Figure 2. TGA plots of TDGEBA/SAA epoxy cured with TETA and modified with PE (a) TDGEBA/SAA-PE (95/5); (b) TDGEBA/SAA-PE (90/10); (c) TDGEBA/SAA-PE (85/15); (d) TDGEBA/SAA-PE (80/20) in presence of benzoyl peroxide as initiator at $\left(85^{\circ} \mathrm{C}\right)$. 
atures required to attain the same weight losses for modified 5\% PE Figure 2(a) are found to be decreased to $292^{\circ} \mathrm{C}, 400$ and $429^{\circ} \mathrm{C}$ respectfully. A similar trend is observed $20 \%, 30 \%$ and $40 \%$ PE modified TDGEBA/ SAA epoxy. The thermal stability is slightly less than that of 5\%, PE modified TDGEBA/SAA epoxy. For example, the temperature require for $10 \%$ and $30 \%$ weight loss of unmodified TDGEBA/SAA epoxy resin Figure 1 (b) are $360^{\circ} \mathrm{C}$ and $402^{\circ} \mathrm{C}$ comparing with $30 \% \mathrm{PE}$ modified at the same weight loss are found $330^{\circ} \mathrm{C}$ and $375^{\circ} \mathrm{C}$ respectively, the thermal results of unmodified and modified TDGEBA/SAA epoxy resins are presented in Table 1. From the table it is evident that the thermal stability of modified epoxy resins increasing comparing with uncuring and unmodified TDGEBA/SAA epoxy and slightly decreases with increasing of PE concentration comparing with TDGEBA/SAA epoxy cured with TETA alone This may be explained due to the presence of flexible-o-o-polyester linkage Figures 3(a)-(b).

\subsection{Mechanical Properties}

In developing high-performance epoxy polymer mixtures on two immiscible polymers, the objective is to raise the compatibility of these two components. Compatibilized poly mixtures have finer phase domain size and greater interfacial contact area and interfacial adhesion than the corresponding uncompatibilized mixtures, as shown in the SEM morphologies, so a given stress can be transferred efficiently between phase domains.

Unnotched impact strength is commonly used to differentiate toughness change resulting from compatibilization for notch sensitive blends. Table 2 presents the effects of PE contents on the impact strength and hardness

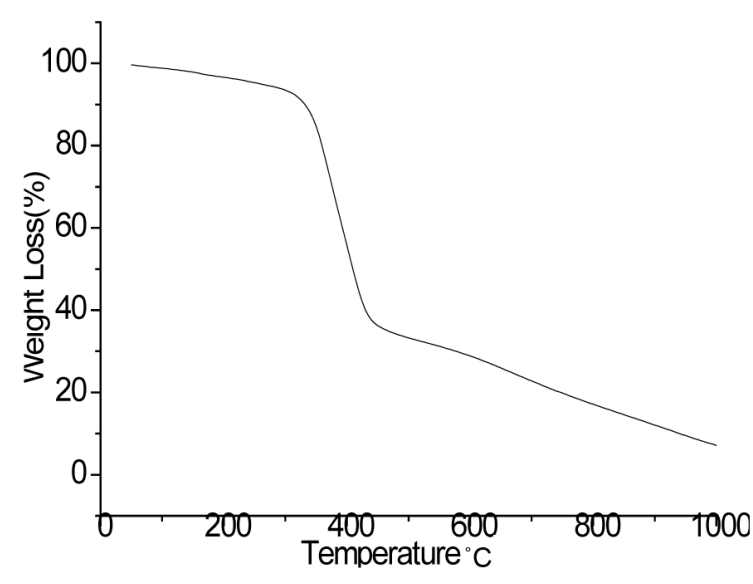

(a)

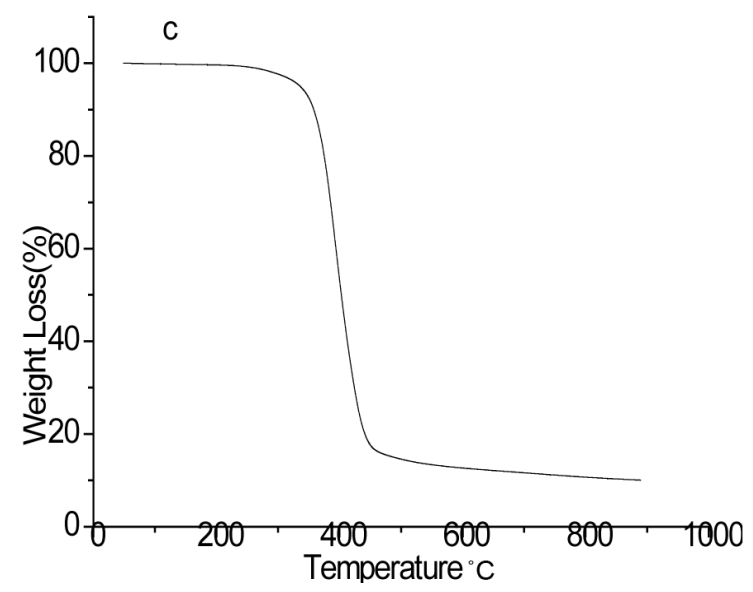

(c)

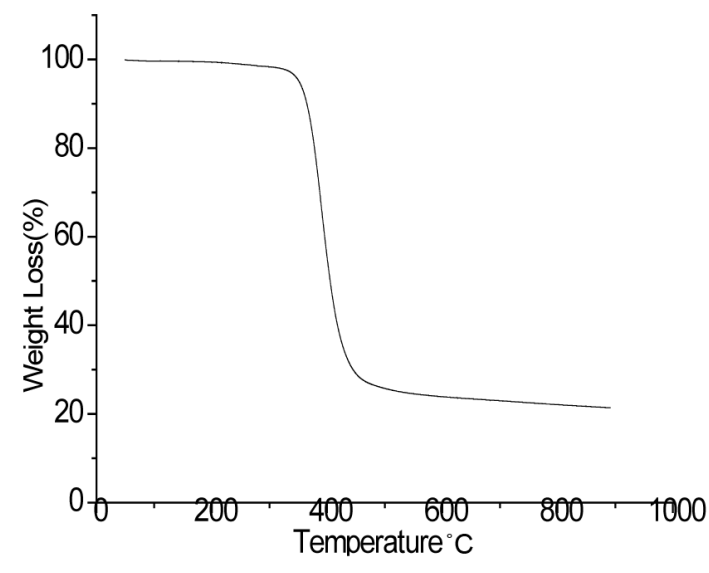

(b)

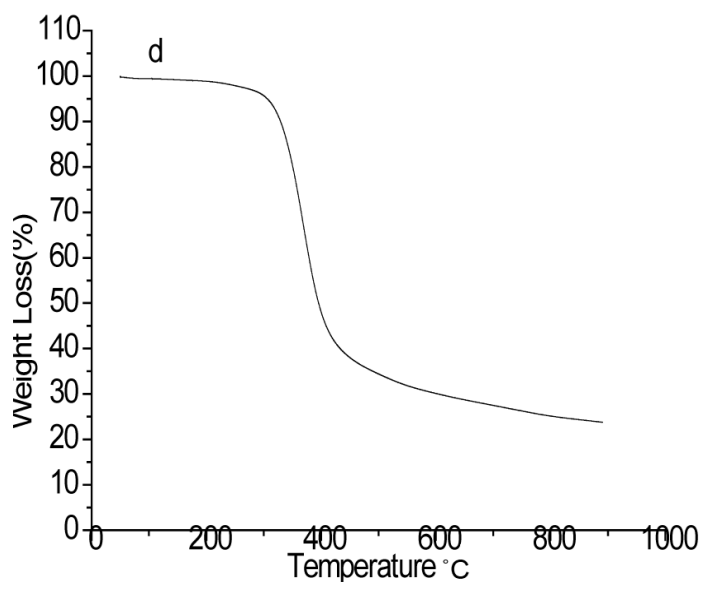

(d)

Figure 3. TGA plots of TDGEBA/SAA epoxy cured with TETA and modified with PE (a) TDGEBA/SAA-PE (70/30); (b) TDGEBA/SAA-PE (60/40); (C) TDGEBA/SAA-PE (50/50); (d) TDGEBA /SAA-PE (40/60) in presence of benzoylperoxide as initiator at $\left(85^{\circ} \mathrm{C}\right)$. 
properties of the unmodified and modified TDGEBA/SAA epoxy systems with PE mixtures.

Because of the poor cured TDGEBA/SAA epoxy systems compatibility between TDGEBA and SAA, the impact strength properties of the unmodified TDGEBA/SAA epoxy mixtures are less than desirable. The trend of unnotched impact strength for TDGEBA/SAA epoxy mixture with various amounts of PE is consistent with corresponding hardens properties. PE exhibits a significant effect on the enhancement of impact strength properties for TDGEBA/SAA epoxy mixture, which can be attributed to the in situ-formed TDGEBA/SAA epoxy with PE polymer network molecules anchoring along the interface. A greater number of in situ polymer network molecules tend to be produced with increasing the quantity of PE and anchor along the interface as the result of chemical reaction. The PE has demonstrated combination of TDGEBA/SAA and PE to be an excellent reactive improvement in their impact strength properties due to internal Stress decreasing of cured TDGEBA/SAA epoxy.

The results on impact resistance, hardness, solvent resistance and hardening time Table 2 shows the unmodified and modified tetra diglycidyl ether bisphenol-A Sulphanilamide TDGEBA/SAA epoxy systems with PE. In case of modified. The solvent resistance and impact strength increased initially up to a TDGEBA/SAA epoxy resin with PE mixture ratio of 40:60 (w/w), increased more than $30 \%$ than the unmodified epoxy resin) and hardness that is found to be higher than unmodified epoxy resin. This can be explained based on characteristically good compatibility of PE with TDGEBA/SAA, epoxy systems.

\subsection{Scanning Electron Microscopy (SEM)}

Figure 4 exhibits the fracture surface examined using SEM. The neat a tetra diglycidyl ether bisphenol-A Sulphanilamide TDGEBA/SAA epoxy as well as modified TDGEBA/SAA epoxy resin with PE in the presence of TETA morphology of some selected samples is shown in the Figures 4(a)-(d). Which were recorded after testing the samples for unnotched Izod impact strength In case of neat TDGEBA/SAA (100\%) epoxy sample Figure 4(a) the fracture surfaces shows typical characteristics of brittle fracture and have poor impact properties. These relative to their respective components due to their high interfacial tension, leading to poor control of morphology and stress transfer under loading in solid state. An efficient compatibilizer in the mixture can reduce the interfacial tension or internal stress and enhance the interfacial adhesion between TDGEBA/SAA epoxy modified with PE thus improves its impact strength properties. Figures 4(b)-(d) show the unnotched SEM micrograph of the fractured surface of the TDGEBA/SAA modified with PE $(10 \%-30 \%)$. The large dispersed and spherical TDGEBA/SAA epoxy particles with different dimensions can be easily identified from these uncompatibilized mixtures due to the incompatibility of these two polymers.

The interface between TDGEBA/SAA epoxy modified with PE is quite sharp, an indication of low interfacial adhesion. Figures 4(b)-(d) present the unnotched SEM micrographs of cryogenic-fractured surfaces of TDGEBA/SAA-PE series mixtures containing various amounts of PE. The general trend indicates that the dispersed TDGEBA/SAA epoxy particle size decreases with the increase of PE content. Figures 4(b)-(d) shows the fractured surface of the TDGEBA/SAA modified with (10\%, 20\% and 30\%) respectively after solvent etching. The empty holes are the dispersed PE phase mixture etched out of the mixture by solvent. The sizes of the neat TDGEBA/SAA epoxy particles decrease obviously with increasing the amounts of PE in the neat TDGEBA/SAA series mixtures, as presented in Figure 4(a) and Figure 4(b).

The TDGEBA/SAA epoxy modified with polyester PE $(60,40) \%$ Figure 5(a) exhibits homogeneity in morphology with finer crystallites and lower void space, which is expected to render better impact strength to the material. Further, modification TDGEBA/SAA-P (50/50) also shows smooth nature and crystallites spread more homogenously in the matrix sample Figure 5(b) however exhibits large aggregates with some fracture bounders separating them.

The reduction of the TDGEBA/SAA epoxy phase domain in the mixture can be attributed to the better compatibilization through the formation of TDGEBA/SAA-PE (50/50) mixture in these compatibilized mixtures. Owing to the relatively low molecular weight, PE can diffuse easily between the constituent components, react with TDGEBA/SAA, and produce the desired epoxy polymer networks at the interface. The finer phase domains are the indication of better compatibilization of the mixtures. That the main advantage of using compatibilizer in epoxy polymer networks is the suppression of coalescence achieved through stabilizing the interface, not a reduction in the interfacial tension.

Figure 4 illustrates that the in situ-formed compatibilizers reduce the interfacial tension during melt mixing and result in a smaller domain size of the dispersed phase particles. 


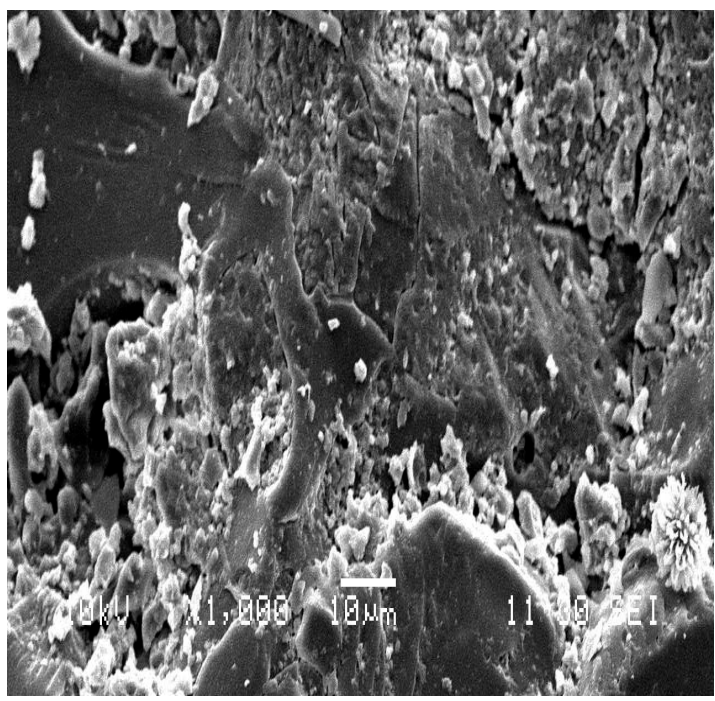

(a)

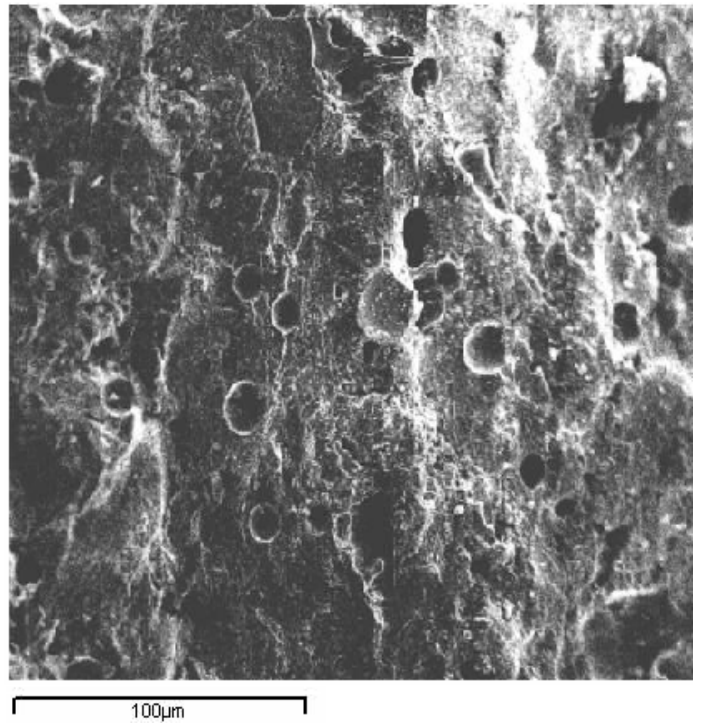

(c)

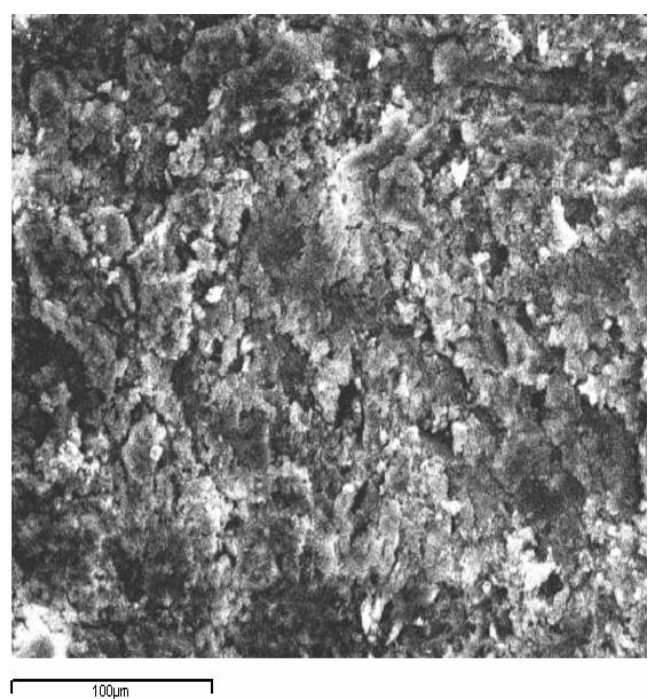

(b)

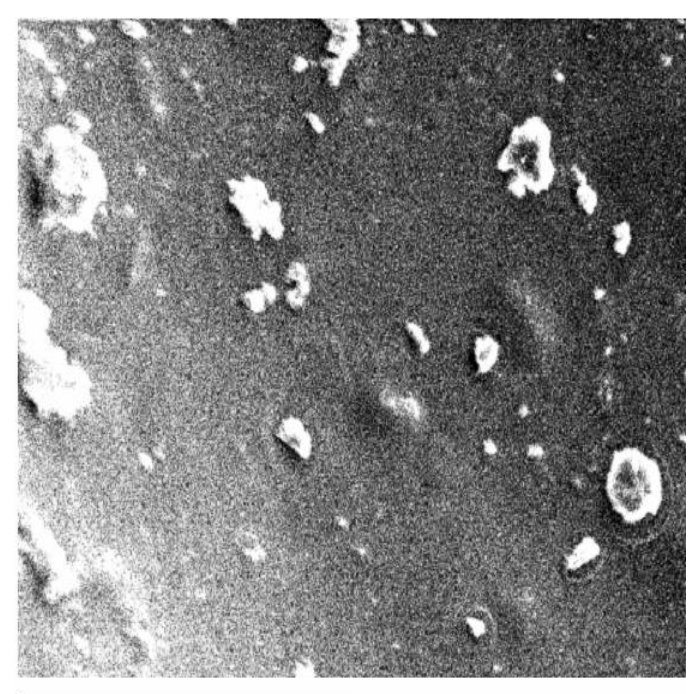

(d)

Figure 4. SEM morphologies after impact fractured surfaces for cured neat TDGEBA/SAA epoxy with TETA and modified with various PE contents. (a) Neat TDGEBA/SAA = 100\%; (b) TDGEBA/SAA-PE = 90/10; (c) TDGEBA/SAA-PE = 80/20 and $(d)$ TDGEBA/SAA-PE $=70 / 30$ in presence of benzoyl peroxide as initiator at $\left(85^{\circ} \mathrm{C}\right)$.

\section{Conclusions}

A series of TDGEBA/SAA epoxy resin cured with TETA and modified polyester were prepared by a reaction of epoxy resin with a functionalized PE using external hardener. The reaction between epoxy and hardener occurs via ring opening of the epoxide ring by the hydroxyl functionalities present on the PE and these results in the formation of a network structure. The curing of epoxy with the reactive TETA was found high thermal stability as confirmed by DSC. Viscoelastic analyses showed that the glass transition temperature shifted from $350^{\circ} \mathrm{C}$ to $400^{\circ} \mathrm{C}$ and higher impact strength with the increase of polyester content, which reflected the miscibility between epoxy and polyester. This product had excellent solvent resistance, which also proved the formation of the network structure between the epoxy matrix and polyester. TGA showed that the cured TDGEBA/SAA epoxy resins are thermally more stable than the epoxy cured with the traditional diamines.

The increase of the polyester content led to increase of the impact strength and thermal stability of the epoxy compared with uncured and unmodified TDGEBA/SAA epoxy resins. 


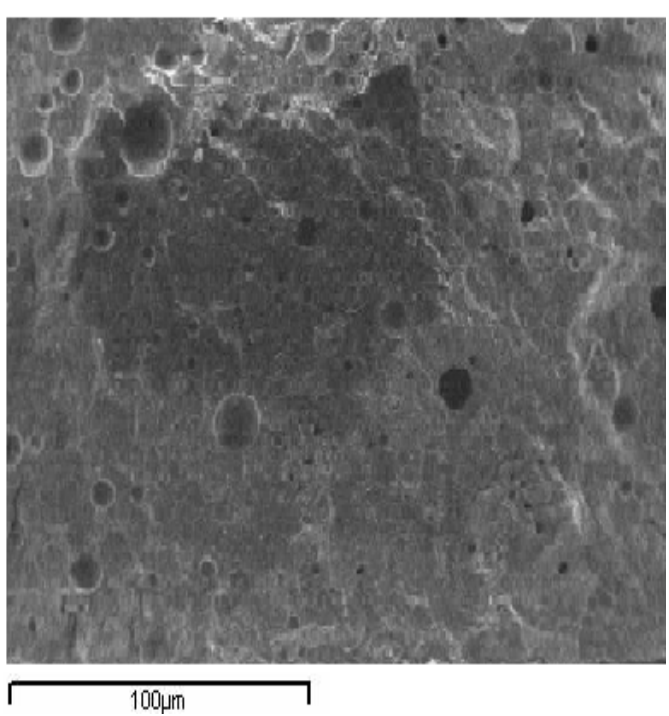

(a)

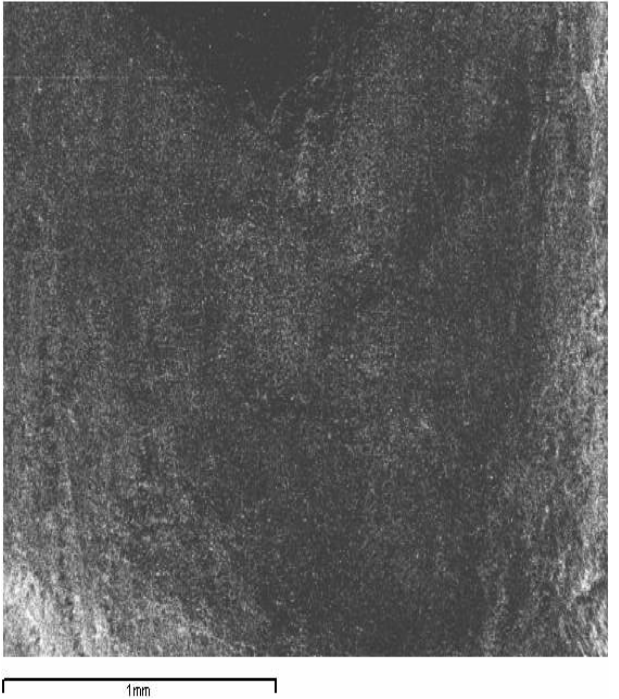

(b)

Figure 5. SEM morphologies after impact-fractured surfaces for the TDGEBA/SAA modified PE, (a) TDGEBA/SAA-PE = 60/40; (b) TDGEBA/SAA-PE $=50 / 50$ in presence of benzoyl Peroxide as initiator at $\left(85^{\circ} \mathrm{C}\right)$.

\section{Acknowledgements}

The authors like to thank Department of Chemistry, Sardar Patel University, particularly Prof. A. K. Ray and NCL for helping in measurement. They also would like to acknowledge C.N.Q.S. Department of Physics, University of Pune INDIA and Ministry of higher education, Yemen for financial support.

\section{References}

[1] Ju, M.-Y. and Chang, F.-C. (1999) Polymer Blends of PET-PS Compatibilized by SMA and Epoxy Dual Compatibilizers. Journal of Applied Polymer Science, 73, 2029-2040. http://dx.doi.org/10.1002/(SICI)1097-4628(19990906)73:10<2029::AID-APP21>3.0.CO;2-U

[2] Roşu, D., Mititelu, A. and Caşcaval, C.N. (2004) Cure Kinetics of a Liquid-Crystalline Epoxy Resin Studied by NonIsothermal Data. Polymer Testing, 23, 23209-23215. http://dx.doi.org/10.1016/S0142-9418(03)00082-5

[3] Agag, T. and Takeichi, T. (1999) Synthesis and Characterization of Epoxy Film Cured with Reactive Polyimide. Polymer, 40, 6557-6563. http://dx.doi.org/10.1016/S0032-3861(99)00026-9

[4] Micco, G., Giamberini, M., Amendola, E., Carfagna, C. and Astarita, G. (1997) Modelling of Curing Reaction Kinetics in Liquid-Crystalline Epoxy Resins. Industrial Engineering Chemistry Research, 36, 2976. http://dx.doi.org/10.1021/ie9606810

[5] Ameer, A.A., Abdallh, M.S., Ahmed, A.A. and Yousif, E.A. (2013) Synthesis and Characterization of Polyvinyl Chloride Chemically Modified by Amines. Open Journal of Polymer Chemistry, 3, 11-15. http://dx.doi.org/10.4236/ojpchem.2013.31003

[6] Gun-Soo, L. and Myoung-Seon, G. (2001) Preparation of Epoxy Resins Containing Ether Ether Sulfone Unit and Thermal Properties. Bulletin of the Korean Chemical Society, 22, 1393-1396.

[7] Kun-Soo, L., Young-Chul, L., Bong-Gyoo, C. and Myoung-Seon, G. (2001) Preparation of Epoxy Resins Containing Ether Ether Ketene Unit and Their Thermal Properties. Bulletin of the Korean Chemical Society, 22, 424-426.

[8] Athawale, A.A. and Alhousami, M.H.M. (2009) Epoxy Resin-Modified, Urea-Formaldehyde/Silicon Net Works for High Impact Strength and Thermal Stability. Journal of Reinforced Plastics and Composites, 28, 2231-2239. http://dx.doi.org/10.1177/0731684408092366

[9] Ren, H., Sun, J.Z., Wu, B.J. and Zhou, Q.Y. (2007) Synthesis and Properties of Phosphorus-Containing Flam Retardant Epoxy Resin Based on Bis-Phenoxy (3-Hydroxy) Phenyl Phosphine Oxide. Polymer Degradation and Stability. 92, 956-961. http://dx.doi.org/10.1016/j.polymdegradstab.2007.03.006

[10] Iijima, T., Aral, N., Fukuda, W. and Tomoi, M. (1995) Toughening of Aromatic Diamine-Cured Epoxy Resins by Poly (Ethylene Phthalate)s and the Related co Polyesters. European Polymer Journal, 3, 275-284. 
http://dx.doi.org/10.1016/0014-3057(94)00154-5

[11] Jang, J. and Shin, S. (1995) Toughness Improvement of Tetrafunctional Epoxy Resin by Using Hydrolysed Poly(Ether Amide). Polymer, 6, 1199-1207. http://dx.doi.org/10.1016/0032-3861(95)93921-8

[12] Yang, G., Fu, S.-Y. and Yang, J.-P. (2007) Preparation and Mechanical Properties of Modified Epoxy Resins with Flexible Diamines. Polymer, 48, 202-310. http://dx.doi.org/10.1016/j.polymer.2006.11.031

[13] Mercado, L.A., Galià, M. and Reina, J.A. (2006) Silicon-Containing Flame Retardant Epoxy Resins: Synthesis, Characterization and Properties. Polymer Degradation and Stability, 91, 2588-2594. http://dx.doi.org/10.1016/j.polymdegradstab.2006.05.007

[14] Pugliaa, D., Manfredib, L.B., Vazquezb, A. and Kenny, J.M. (2001) Thermal Degradation and Fire Resistance of Epoxy-Amine-Phenolic Blends. Polymer Degradation and Stability, 73, 521-527. http://dx.doi.org/10.1016/S0141-3910(01)00157-4

[15] Perrin, F.X., Nguyen, T.M.H., Tran, T.M.L. and Vernet, J.L. (2006) Determination of Bisphenol A (BPA) by Gas Chromatography-Mass Spectrometry and ${ }^{1} \mathrm{H}$ NMR Spectroscopy during Curing of Epoxy-Amine Resins. Polymer Testing, 25, 912-922. http://dx.doi.org/10.1016/j.polymertesting.2006.05.015

[16] El Gersifi, K., Destais-Orvoën, N., Durand, G. and Tersac, G. (2003) Glycolysis of Epoxide-Amine Hardened Networks. I. Diglycidylether/Aliphatic Amines Model Networks. Polymer, 44, 3795-3801. http://dx.doi.org/10.1016/S0032-3861(03)00324-0

[17] Mimura, K., Ito, H. and Fujioka, H. (2001) Toughening of Epoxy Resin Modified with in Situ Polymerized Thermoplastic Polymers. Polymer, 42, 9223-9233. http://dx.doi.org/10.1016/S0032-3861(01)00460-8

[18] Merrit, M.E., Heux, L., Halary, J.L. and Schaefer, J. (1997) Determination of the Extent of Reaction of Amine Cross-Linked Epoxy Resins by Solid-State ${ }^{13} \mathrm{C}$ and ${ }^{15} \mathrm{~N}$ NMR. Macromolecules, 30, 6760-6763. http://dx.doi.org/10.1021/ma970757j

[19] Barie Jr., W.P. and Franke, N.W. (1969) High-Temperature Epoxy Resins Based on 3,3,4,4-Benzophenoeteracarboxyic Dianhydride (BTDA). I.EC Product Research and Development, 1, 72-76.

[20] Mohammadnia, M.S., Salaryan, P., Azimi, Z.K. and Seyidov, F.T. (2012) Preparation and Characterization of Polyesters with Controlled Molecular Weight Method. International Journal of Chemical and Biochemical Sciences, 2, 36-41.

[21] Watts, J.F., M.-L. Abel, Perruchot, C., Loweb, C., Maxted, J.T. and White, R.G. (2001) Segregation and Crosslinking in Urea Formaldehyde/Epoxy Resins: A Study by High-Resolution XPS. Journal of Electron Spectroscopy and Related Phenomena, 121, 233-247. http://dx.doi.org/10.1016/S0368-2048(01)00337-1

[22] Huang, M.L. and Williams, J.G. (1994) Mechanisms of Solidification of Epoxy-Amine Resins during Cure. Macromolecules, 27, 7423-7428.

[23] Lo, E.S. (1960) An Epoxy Resin from Phenolphthalein. Industrial \& Engineering Chemistry, 52, 319-326.

[24] Bader, M.G., Bailey, J.E. and Bell, I. (1973) The Effect of Fibre-Matrix Interface Strength on the Impact and Fracture Properties of Carbon-Fibre Reinforced Epoxy Resin Composites. Journal of Physics D: Applied Physics, 6, 572-586. http://dx.doi.org/10.1016/S0368-2048(01)00337-1

[25] Ju, M.-Y. and Chang, F.-G. (1999) Polymer Blends of PET-PS Compatibilized by SMA and Epoxy Dual Compatibilizers. Journal of Applied Polymer Science, 73, 2029-2040. http://dx.doi.org/10.1002/(SICI)1097-4628(19990906)73:10<2029::AID-APP21>3.0.CO;2-U

[26] Soldatos, A.C. and Burhans, A.S. (1970) Cycloaliphatic Epoxy Resins with Improved Strength and Impact Coupled with High Heat Distortion Temperature. Industrial \& Engineering Chemistry, 3, 296-300.

[27] Lin, J.-J., Lin, S.-F., Kuo, T.-T., Chang, F.-C. and Tseng, F.-P. (2000) Synthesis and Epoxy Curing of Mannich Bases Derived from Bisphenol A and Poly(Oxyalkylene) Diamine. Journal of Applied Polymer Science, 78, 615-623. http://dx.doi.org/10.1002/1097-4628(20001017)78:3<615::AID-APP170>3.0.CO;2-N

[28] Wang, M.S. and Pinnavaia, T.J. (1994) Clay-Polymer Nanocomposites Formed from Acidic Derivatives of Montmorillonite and an Epoxy Resin. Chemistry of Materials, 6, 468-474. http://dx.doi.org/10.1021/cm00040a022

[29] Vanaja, A. and Rao, R.M.V.G.K. (2002) Synthesis and Characterisation of Epoxy-Novolac/Bismaleimide Networks. European Polymer Journal, 38, 187-193. http://dx.doi.org/10.1016/S0014-3057(01)00094-5

[30] Chen, S., Tian, Y., Chen, L. and Hu, T. (2006) Epoxy Resin/Polyurethane Hybrid Networks Synthesized by Frontal Polymerization. Chemistry of Materials, 18, 2159-2163.

[31] Tieke, B. and Zahir, S.A. (1993) Anew Cross-Linkable Palladium (0) Complex and Its Use for Electroless Metallization of Epoxy Resins. Chemistry of Materials, 5, 891-897. http://dx.doi.org/10.1021/cm00030a028

[32] Levchik, S.V., Camino, G., Luda, M.P., Costa, L., Henry, B.C.Y., Muller, G. and Morel, E. (1995) Mechanistic Study of Thermal Behaviour and Combustion Performance of Epoxy Resins 11 GDDM/DDS System. Polymer Degradation 
and Stability, 24, 359-370. http://dx.doi.org/10.1016/0141-3910(95)00084-Y

[33] Ambrogi, V., Giamberini, M., Cerruti, P., Pucci, P., Menna, N., Mascolo, R. and Carfgne, C. (2005) Liquid Crystalline Elastomers Based on Diglycidyl Terminated Rigid Monomers and Aliphatic Acids. Part 1. Synthesis and Characterization. Polymer, 46, 2105-2121. http://dx.doi.org/10.1016/j.polymer.2005.01.007

[34] Merritt, M.E., Goetz, J.M., Whitney, D., Paul, C.-P., Heux, L., Halary, J.L. and Schaefer, J. (1998) Location of the Antiplasticizer in Cross-Linked Epoxy Resins by ${ }^{2} \mathrm{H},{ }^{15} \mathrm{~N}$ and ${ }^{13} \mathrm{C}$ REDOR NMR. Macromolecules, 31, 1214-1220. http://dx.doi.org/10.1021/ma9708306

[35] Jansen, B.J.P., Tamminga, K.Y., Meijer, H.E.H. and Lemstra, P.J. (1999) Preparation of Thermoset Rubbery Epoxy Particles as Novel Toughening Modifiers for Glassy Epoxy Resins. Polymer, 40, 5601-5607. http://dx.doi.org/10.1016/S0032-3861(98)00774-5 
Scientific Research Publishing (SCIRP) is one of the largest Open Access journal publishers. It is currently publishing more than 200 open access, online, peer-reviewed journals covering a wide range of academic disciplines. SCIRP serves the worldwide academic communities and contributes to the progress and application of science with its publication.

Other selected journals from SCIRP are listed as below. Submit your manuscript to us via either submit@scirp.org or Online Submission Portal.
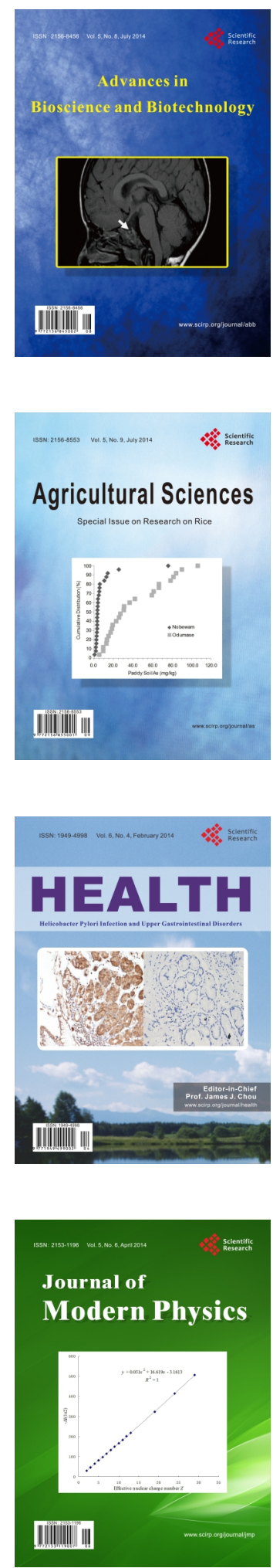
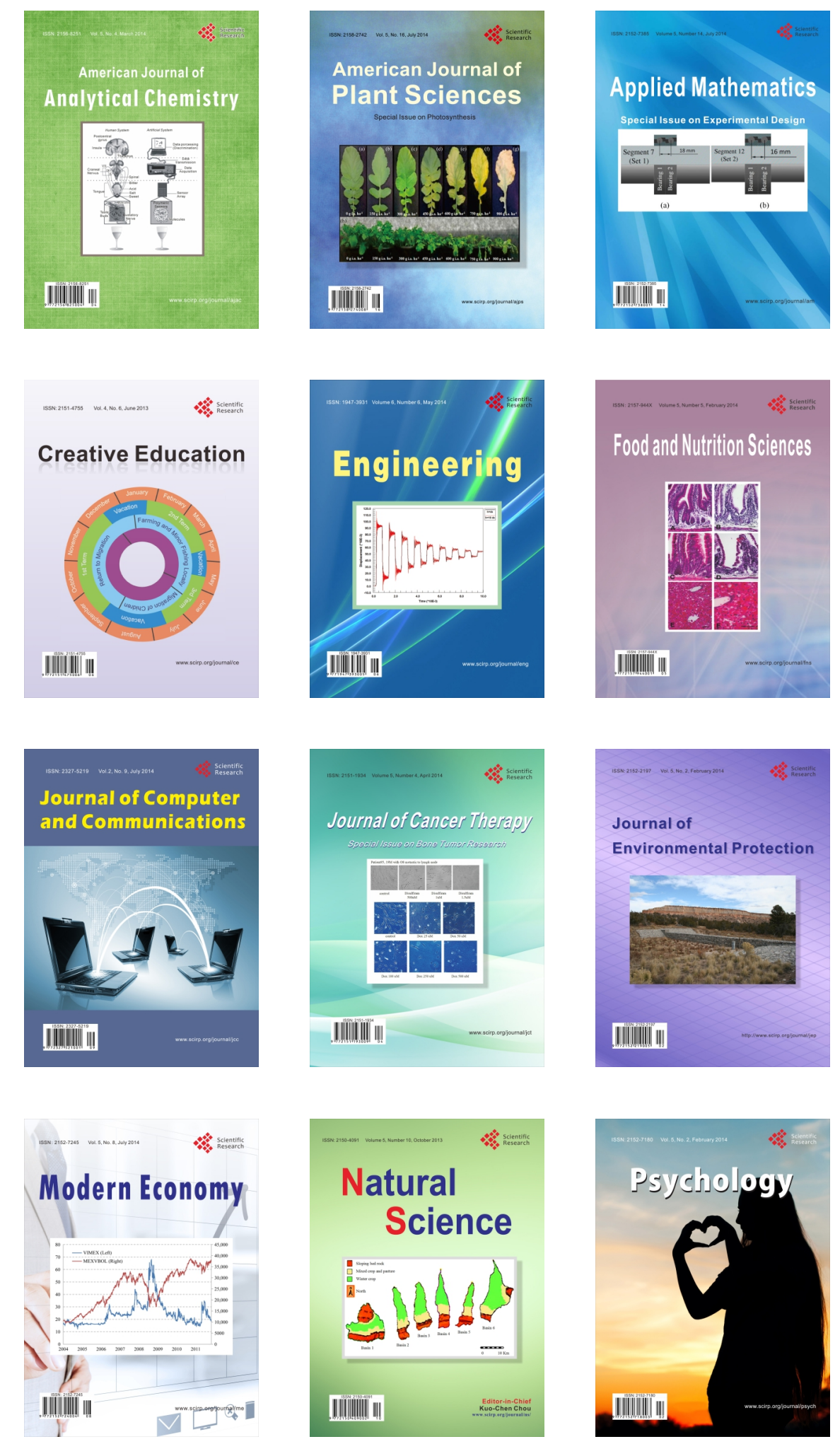